\title{
Differential acquisition-stage emphasis, instructions, and verbal mediating responses'
}

\author{
MARGARET JEAN PETERSON AND SARAH D. HILLNER
}

INDIANA UNIVERSITY

The first experiment investigated the effects upon mediated responding of instructions and of the "emphasis" given to acquisition-stage items. Mediated responding was greater when instructions encouraged selection of the critical response, $C$, than when instructions discouraged selection of the critical response, $C$. In most cases, emphasis of items during the acquisition stages facilitated efficient utilization of the instructions on the test trial. A second experiment showed that emphasis of items during the acquisition stages aided identification of the critical res ponse on eight-alternative test trials.

In an earlier experiment, Peterson \& Hillner (1966) systematically emphasized items appearing in various positions of a $\mathrm{B}-\mathrm{C}, \mathrm{B}-\mathrm{A}, \mathrm{A}-\mathrm{CDE}$ mediation paradigm by printing them in red. The control paradigm, $\mathrm{X}-\mathrm{C}$, B-A, A-CDE, was shown under the same emphasisconditions as the mediation paradigm. Mediated responding was reliably evinced only when Ss reported attempts to select the previously seen response, C, on the test trial and was greatest when both stimulus terms of the acquisition pairs had been emphasized or when $\mathrm{C}$ had been emphasized as a first-pair responseterm. When Ss reported the use of other strategies on the test trial, no evidence of mediated responding was obtained for any of the emphasis-conditions. These results could be interpreted as suggesting that mediated responding necessarily involves conscious processes. However, the analysis was based on the postexperimental reports of the $\mathrm{Ss}$, and it was deemed desirable to replicate the experiment using instructions to encourage or discourage selection of the critical response on the test trial. Mediated responding should be greater with "Encourage" instructions than with
"Discourage" instructions. Also, the application of the instructions might be influenced by emphasizing items in different positions in the acquisition pairs if execution of the instructions were easier with salient items (items that had been printed in red or had been associated with items printed in red) than with items of lower salience (i.e., non-emphasized items). Experiment I was designed to test these predictions.

\section{Method}

\section{EXPERIMENT I}

The experimental materials were taken from Peterson \& Hillner (1966). The general experimental procedure was to present 48 "sets" to each S. A "set" consisted of the consecutive presentation of five cards. The first card showed the first acquisition pair (e.g., $\mathrm{B}-\mathrm{C})$. The second card tested the immediate retention of the first acquisition pair by showing the stimulus, $B$, alone. The third card carried the second acquisition pair, B-A, and the fourth card tested the immediate retention of the second pair by showing $B$ alone. The last, test-trial, card presented the response term from from the second acquisition pair, $A$, as the stimulus for three response alternatives, including the response term of the first acquisition pair, C. Thus a mediation set was identified as B-C, B, B-A, B, A-CDE. Its control set differed only in the substitution of a new item for the stimulus of the first pair, yielding the paradigm $\mathrm{X}-\mathrm{C}, \mathrm{X}, \mathrm{B}-\mathrm{A}, \mathrm{B}, \mathrm{A}-\mathrm{CDE}$. The position of $\mathrm{C}$ among the alternatives on the test trials was balanced and the $D$ and $\mathrm{E}$ alternatives were $\mathrm{C}$ alternatives from other sets. The mediation and control sets were constructed from $87-100 \%$ association value CVC trigrams.

Half of the sets presented to $S$ were mediation sets and half were control sets. In addition, four emphasis-

Table 1. The Experimental Paradigms, Mean Selections (Exp. I) and Identifications (Exp. II) of C on Test Trials.

\begin{tabular}{|c|c|c|c|c|c|c|c|c|c|c|c|c|}
\hline Type of Presentation & Mediati & & & & & & Control & & & & & \\
\hline Acquisition-Stage Emphasis & $\mathrm{C}$ & A & $\mathrm{CA}$ & $\mathrm{B}$ & B* & Black & $\mathrm{C}$ & A & $\mathrm{CA}$ & B & $\mathrm{B}^{*}$ & Black \\
\hline First Stage & $\mathrm{B}-\mathrm{C}$ & B-C & $\mathrm{B}-\mathrm{C}$ & $B-\mathrm{C}$ & $B-C$ & $B-C$ & $\mathrm{X}-\mathrm{C}$ & $\mathrm{X}-\mathrm{C}$ & $\mathrm{X}-\mathrm{C}$ & $X-\mathrm{C}$ & $X-C$ & $\mathrm{X}-\mathrm{C}$ \\
\hline Retention Test & B & B & B & $B$ & B & $\mathrm{B}$ & $\mathrm{x}$ & $\mathrm{x}$ & $\mathrm{x}$ & $X$ & $\mathrm{x}$ & $\mathrm{x}$ \\
\hline Second Stage & B-A & B- $A$ & B- $A$ & $B-A$ & $B-A$ & B-A & B-A & $\mathrm{B}-A$ & B- $A$ & $B-A$ & $B-A$ & B-A \\
\hline Retention Test & $\mathrm{B}$ & B & B & $B$ & B & $\mathrm{B}$ & $\mathbf{B}$ & B & B & $B$ & & B \\
\hline Test Stage (Exp. I) & A-CDE & $\mathrm{A}-\mathrm{CDE}$ & A-CDE & A-CDE & A-CDE & $A-C D E$ & $\mathrm{~A}-\mathrm{CDE}$ & $A-C D E$ & A-CDE & A-CDE & $\mathrm{A}-\mathrm{CDE}$ & $A-C D E$ \\
\hline Test Stage (Exp. II) $a$ & $\mathrm{C}, \ldots, \mathrm{J}$ & $\mathrm{C}, \ldots, \mathrm{J}$ & $\mathrm{C}, \ldots, \mathrm{J}$ & $\mathrm{C}, \ldots, \mathrm{J}$ & $\mathrm{C}_{,} \ldots, \mathrm{J}$ & $\mathrm{C}, \ldots, \mathrm{J}$ & $\mathrm{C}, \ldots, \mathrm{J}$ & $\mathrm{C}, \ldots, \mathrm{J}$ & $\mathrm{C}, \ldots, \mathrm{J}$ & $\mathrm{C}, \ldots, \mathrm{J}$ & $\mathrm{C}, \ldots, \mathrm{J}$ & $\mathrm{C}, \ldots, \mathrm{J}$ \\
\hline So & $\mathrm{C}$ on $\mathrm{t}$ & the tes & rials & & & & & & & & & \\
\hline Encourage instructions & 4.88 & & 4.81 & 4.84 & & 4.72 & 4.56 & & 4.19 & 4.34 & & 4.59 \\
\hline Discourage instructions & 2.32 & & 2.41 & 2.72 & & 2.56 & 2.25 & & 2.63 & 2.38 & & 3.03 \\
\hline & & & & & & & & & & & & \\
\hline Mean & 4.96 & 4.58 & 5.00 & 5.09 & 5.42 & 4.96 & 4.50 & 5.25 & 4.54 & 4.24 & 4.75 & 4.62 \\
\hline
\end{tabular}

a Test stage for each condition had eight alternatives: $C, D, E, F, G, H, I, J$. 
conditions (B, C, CA, Black) were each represented six times among the 24 mediation sets and among the 24 control sets assigned to $\mathrm{S}$. The emphasis-conditions are defined in the upper portion of Table 1. The trigrams in the italicized positions were printed in red ink; all other trigrams were printed in black.

The 64 students from introductory psychology courses were assigned randomly to the two instructional groups. The instructional groups were a between-Scondition and the within-S conditions were used equally often in each instructional group.

The Ss spelled aloud all trigrams shown. On the immediate retention tests, $S$ attempted to give the missing response. If he erred, the acquisition pair was shown again, followed by the stimulus alone. This procedure continued until $S$ correctly stated the response trigram. On the test trials, $\mathrm{S}$ read the stimulus trigram with each of the response alternatives and then stated which of the response alternatives "seemed right" or made the "best pair" with the stimulus. The Ss in the Encourage group were urged to select the response they had just seen. The Ss in the Discourage group were told to concentrate on choosing the best sound combination and to ignore past syllables. The Ss were questioned and dismissed.

\section{Results and Discussion}

The immediate retention of the acquisition pairs was high (99.82\%) and did not differ from condition to condition. The Encourage group provided greater evidence of mediated responding on the test trials than did the Discourage group, $F=11.09, d f=1 / 48$, p .01, (Rows 10 and 11, Table 1). The Encourage group evinced mediated facilitation under the B, the CA, and the $C$ emphasis-conditions, $t^{\prime} ' s=3.62,4.49,2.32$, $\mathrm{df}=144$, $\mathrm{p}^{\prime} \mathrm{s}<.05$, but not under the Black emphasiscondition, $t<1$. With Discourage instructions, Ss tended to select $C$ less often on the test trials of mediation sets than on the test trials of control sets (mediated inhibition). Reliable evidence of mediated inhibition occurred under the Black emphasis-condition, $t=2.81$, $\mathrm{df}=144, \mathrm{p}<.01$, but not under either the $\mathrm{C}$ or the CA emphasis-conditions. The B emphasis-condition showed mediated facilitation, $t=2.04, \mathrm{df}=144, \mathrm{p}<.05$. None of the Ss in the Discourage Instructions Group reported awareness of the experimental paradigm. Hence their performance could be cited as mediated responding which occurred in the absence of conscious attempts to mediate.

Generally, the instructions interacted with the conditions of emphasis to determine the evidence of mediated responding and, for most conditions, execution of the instructions was facilitated by the salience of the items.

The assumption underlying the experimental operations of Experiment $I$ and the Peterson-Hillner (1966) experiment was that emphasis of items during the acquisition stage would facilitate their retention. In both experiments, the immediate recall of $\mathrm{C}$ as the response term of the first acquisition pair was almost perfect but the design did not evaluate retention of $\mathrm{C}$ at the time of the test trial. Experiment II was conducted to assess S's ability to identify the critical response, $C$, from among eight response-alternatives on the test trial.

\section{Method}

\section{EXPERIMENT II}

Six sets representing each of the conditions shown in the upper portion of Table 1 were shown in randomized order to 60 additional Ss drawn from the same source. The test-trials of the sets were modified by omitting the stimulus term, $A$, and increasing the number of response alternatives to eight: $C, D, E, F$, G, H, I, J. The D-J alternatives were trigrams which were used in the $\mathrm{C}$ position for other sets. The presentation-procedure and the instructions read to all Ss in Experiment I were used. The only change concerned the test trials. The Ss were to read off all eight trigrams and to select the one they had seen among the immediately preceding pairs.

\section{Results and Discussion}

Again, the immediate retention of the acquisition pairs was almost perfect. The proportions of $\mathrm{C}$ alternatives correctly identified on the test trials was high, ranging from .71 to .90 . As shown in the lower section of Table $1, \mathrm{C}$ was identified more often following mediation sets than following control sets, $F=16.18, \mathrm{df}=1 / 40$, $p<.01$, particularly for the.$\eta(t=4.47)$, the $B^{*}(t=3.53)$, the $\mathrm{CA}(\mathrm{t}=2.42)$, and the $\mathrm{C}(\mathrm{t}=2.42)$ emphasis-conditions. The reverse was true for the $A$ emphasis-condition $(t=3.53)$. The Black conditions did not show reliable mediation-control differences. The df for the $t^{\prime} s=120$, p's $<.05$.

These results suggested that the interaction observed with Experiment I and the Peterson-Hillner (1966) experiment occurred because the emphasis-conditions fostered retention of at least the critical response until the test trial. The S could then make a test-trial decision which was consistent with the E-imposed (Experiment I) or self-imposed (Peterson-Hillner) instructions.

\section{References}

Peterson, M. J. Effects of delay intervals and meaningfulness on verbal mediating responses. J. exp. Psychol., 1965, 69, 60-66. Peterson, M. J., \& Hillner, S. D. The effects of differential acquisition-stage emphasis and auto-instructions upon verbal mediating responses. Psychon. Sci., 1966, 5, 63-64.

\section{Note}

1. This research was supported by Grant 07944 , National Institute of Mental Health, United States Public Health Service. The assistance of Susan Wantz is gratefully acknowledged. 